\title{
TELEVISION VIEWING HABITS AND BULLYING OF INTERMEDIATE GRADE SCHOOL CHILDREN
}

\author{
Khadiguia Ontok-Balah, Malt \\ Department of Psychology, College of Arts and Sciences, \\ University of Southern Mindanao (USM), Philippines \\ khads_26@yahoo.com
}

\author{
Jessica C. Garcia \\ Department of Psychology, College of Arts and Sciences, \\ University of Southern Mindanao (USM), Philippines \\ jcgarcia@yahoo.com
}

\begin{abstract}
One of the main factors which influence the children while watching cartoons is violence as it is a vital part of most of the cartoon programs. Through this, children are induced and attracted of violent contents (Hassan and Daniyal, 2013). Studies have shown that children's television programs shown contain 20 violent acts each hour. Using a correlational research design, this study was done to determine the possible relationship between television viewing habits and bullying among intermediate grade school children from Kabacan Pilot Central School, Kabacan, Cotabato. The study revealed varied findings relative to the viewing on TV by the pupils and their level of bullying. For example, it was found out that children who were watching Broadcasting TV Network 3 or TV5 had higher level of bullying than those children who were watching Broadcasting TV Network 2 or GMA. However, the study failed to make any conclusive finding on children who were watching Broadcasting TV Network 1 or ABS-CBN since the result showed that it was not significantly correlated to the level of bullying. Since, this research discovered children with high level of bullying, the result may be sent to the office of the principal in order to inform the class adviser of the children and provide the data to the parents for possible interventions because it might spread bullying in school as a whole.
\end{abstract}

Keywords: television viewing, television viewing habits, bullying, violence, cartoon characters

\section{INTRODUCTION}

Over a short period of time, television served fairly as a new medium of communication, entertainment, and education. Thus, television brought us social changes. In recent years, increased attention has been focused by many professionals with regard to its impact on human lives at any stage of development, especially in the childhood stage. It can be observed that children are fascinated and enticed by animated and cartoon characters. Hence, they spend much of their time watching cartoons on TV and become hooked up on cartoon channels like the Cartoon Network and some cartoon programs shown on Television Broadcasting Networks such as the ABSCBN, GMA7, and the TV5 which reach the young audiences from the cities and provinces in the Philippines.

One of the main factors which influence the children while watching cartoons is violence. Further, violence is a vital part of most of the cartoon programs. Through the cartoon programs, children are induced and attracted of violent contents (Hassan and Daniyal, 2013). Studies have shown that children's television programs shown contain 20 violent acts each hour (APA, 2007). Violence is a learned behaviour and therefore, children need to see violence in order to become violent themselves (Krieg, 2006). If children are viewing their favourite characters hitting, kicking, and beating up the 'bad guys' the children will learn these behaviours too. And because most of these cartoons do not show any consequences for these behaviours and in a sense glorify violence, children think that this is an acceptable form of problem solving, and hence most of the time results in the acts of bullying.

Bullying, on the other hand, is a form of violence against others, whether physical (hitting, kicking, pushing, etc.) or emotional (rejections, put downs, threats, etc.). It can leave those who are bullied feeling powerless and abused. Bullying is serious and can be destructive to the well-being of the children and can lead to long-lasting emotional scars both to the children who bully and to the ones who are bullied. Also, research shows that children who merely witness bullying are also destructed, intimidated, upset, and hurt just as badly as targets. Consequently, children who bully may grow up to be abusive adults. Therefore, school guidance counsellors and/or school psychologists, educators, and parents must become more aware to the negative effects bullying can bring to the overall well-being of the children especially in the school and should work together to reduce its occurrence. Hence, this study is interested to determine the possible relationship between television viewing habits and bullying among intermediate grade school children from Kabacan Pilot Central School, Kabacan, Cotabato.

\section{Significance of the Study}

The outputs of this study shall be beneficial for the parents, the Kabacan Pilot Central School (KPCS) administration, the Psychology practitioners, and the future researchers. The parents of the intermediate grade school children will obtain information based on the result of the study and will make them more aware of how much time their children spend on TV and how television viewing habits influence their children's bullying acts.

For the Kabacan Pilot Central School administration will serve as basis for possible school programs related to children's acts of bullying whenever necessary. Thirdly, the Department of Psychology will benefit on the findings of this study through crafting intervention programs to support parents in guiding their children from potential violence on $\mathrm{TV}$ and its possible contribution to bullying behaviours. Finally, this study will also be useful to the future researchers as it will serve as 
reference in terms of variables related to television viewing habits and how these influence bullying to intermediate grade school children.

\section{Objective of the Study}

The main objective of the study is to determine the television viewing habits and level of bullying of intermediate grade school children in the Kabacan Pilot Central School. Specifically, it aims to: (1) determine the television viewing habits of the respondents (which include the number of hours in watching TV and TV programs watched); (2) determine the level of bullying of the respondents; and; (3) determine the significant relationship between television viewing habits and level of bullying of the respondents.

\section{Hypothesis}

Ho: There is no significant relationship between television viewing habits and bullying of the respondents.

\section{Scope and Limitations of the Study}

The study will be limited only to the Intermediate Grade School Pupils from Kabacan Pilot Central School. The television viewing habits of the respondents are cartoon shows shown on the Broadcast Television Networks (ABS-CBN, GMA and TV5) and on the Cable Television Networks such as Nickelodeon, Cartoon Network, Hero, and Disney Channel. This research will also include the number of hours the respondents watch television based on daily and weekend viewing habits.

\section{THEORETICAL FRAMEWORK}

The study on the relationship between television viewing habits and bullying among intermediate grade school children in the Kabacan Pilot Central School is premised within the Social Learning Theory of Bandura. The theory of Bandura suggests that children may learn aggression from viewing others. Modelling of behaviour was observed in Bandura's Bobo Doll experiments. Bandura showed children a video of a model beating up a Bobo doll and then put the children in a room with a Bobo doll to see if he/she would imitate the behaviour previously seen on the video (Bandura 1963).

Albert Bandura's early research revealed that children's aggressive acts were partly influenced by what they observed (Bandura, 1965). In general, the more aggressive the people or films that children observe, the more aggressive the children act. Learning by watching and imitating others, rather than through one's own personal experiences, is called social learning. Later research has shown that viewing violent acts on TV and in the movies affects people in other negative ways: (1) It decreases viewers' concerns about victims' suffering, (2) it decreases viewers' sensitivity to violent acts, and (3) it increases the likelihood that viewers will emulate the aggressive acts depicted in the show or movie. Young children are especially vulnerable to the effects of observed violence.

\section{Conceptual Framework}

In view of the aforementioned theories, children aggressive acts were partly influenced by what they observed (Bandura, 1965). So, this research is interested to investigate the possible relationship between television viewing habits and bullying acts of grade school children as manifestations of their aggression.

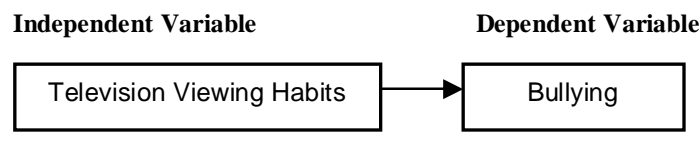

Figure 1 A schematic diagram showing the relationship between TV viewing habits and bullying

\section{Operational Definition of Terms}

Bullying - It is a form of violence against others, whether physical (hitting, kicking, pushing, etc.) or emotional (rejections, put downs, threats, etc.). This refers to the unwanted and aggressive behaviours among school aged children that involves a real or perceived power imbalance. The behaviour is repeated, or has the potential to be repeated, over time. Bullying includes actions such as making threats, spreading rumours, attacking someone physically or verbally, and excluding someone from a group on purpose. This will be measured using the Illinois Bully Scale. The Bully subscale score range from 0-36; the Victim subscale score ranges from 0-16; and the Fighting score ranges from 0-20. Higher scores reflect higher levels of Bullying.

Relationship - Refers to possible relation between television viewing habits and the level of bullying of intermediate grade school. Chi-square will be used to test the relationship of television viewing habits and bullying of the intermediate grade school children.

Respondents - These are the intermediate grade school children who are enrolled in Grades 4 to 6 from the Kabacan Pilot Central School, Kabacan Cotabato.

Television Viewing Habits - These consist of patterns of behaviours which determine the amount of time and importance individuals give to watching television programs. In this study, this will be determined by getting the cartoon programs the respondents watch and the number of hours they spend on the daily basis and during weekends. These are subdivided into three (3) sections: number ofhours; TV programs watched, and frequency and behaviour of the respondents.

\section{Review of Related Literature}

Television programs affect how children behave as what experts have claimed. We already know that most of the children are exposed to a great deal of violence on television. Violence is a vital part of most of the cartoon programs. According to American Psychological Association, research has shown that TV violence negatively affects children.

\section{Television Viewing Habits}


These days, television is everywhere, not just in our living rooms but in bathrooms, kitchens, classrooms and many other places. Adults aren't the only ones watching TV; children today are watching more TV than ever before. The "shape" of the day remains the most important barometer in measuring TV viewing. It is so simple, straightforward and says a lot. In the Philippines, the Movie and Television Review and Classification Board, commonly known as MTRCB, implements and regulates local television content rating systems. On October 6, 2011, in order to encourage parents to supervise and be responsible with their children in watching television, the MTRCB refurbished its rating system, implementing a threetiered system. The new ratings was originally to have been a four-tiered system, composed of $G$ (General Patronage), PG (Parental Guidance), SPG (Strong Parental Guidance), and M, but sometime before the implementation of the new system, the " $\mathrm{M}$ " rating was dropped. $G$ or General Patronage: Any materials being shown in the television does not contain anything unsuitable for children. PG or Parental Guidance: Suggests the parents' guide in watching the show as some of the show may contain adult materials that are only permissible to children under the guidance of supervising adult or their parents. SPG or Strong Parental Guidance: More vigilant and stronger parental guidance is advised. TV programs that are rated "SPG" may contain more serious topic and scenes that are not suitable for very young audiences except with the presence of parents or supervising adult.

The shapes in rural and urban are the same during weekends and weekdays, with two peaks very observable. Still, the highest draws are the Noontime and primetime. The viewing in rural Philippines is slightly lower during daytime and late at night. Ratings from rural Philippines are higher during primetime. It peaks earlier than their urban counterparts and it is true for both weekdays and weekends. Also evident is that rural viewers give up a bit earlier than their urban counterparts. For the past two months, morning viewing in rural areas during weekends mimics the viewing pattern in urban areas (Osorio, 2012). In the morning, rural kids watch about the same amount of TV compared to their urban counterparts, which lasts up to 8:30 a.m. Then, just like the housewives, they watch less TV at noon and in the afternoon. Their viewing picks up and surpasses urban viewing at around 5:30 p.m. and lasts up to 8:30 p.m. This explains the difference among kids and teens in their choices as to the number-one program if you go urban versus rural (Osorio, 2012).

Regarding on how much is there on Philippine TV. According to the study of the National Television Violence (2005), 50\% of TV programs contain violence. The average number of violent incident is 6.2 incident per hour. For every hour of TV viewing there are 6.2 incidents of violence. On average for every 10 minutes there is one violent incident. Violence occurs most often in action/adventure programs (31.6\%) followed by drama (26.3\%), situation comedies (10.5\%), variety shows, (7.9\%), and MTV (7.9\%). According AC Nielsen (2009), 2 to 12 years olds spend
2.8 hours watching TV. One of the study showed that teachers noticed the children have been more obsessed with characters; they write stories, draw pictures and build models of their favorite characters during school. In a survey done on 56 elementary teachers, $88 \%$ reported that they were concerned about the effects of cartoons such as the Power Rangers on their students. Of those teachers surveyed, $96 \%$ of them reported that violence had increased among the children in their classes recently. They also noticed that on the playground boys were increasing excluding girls from play (Walsh, 2014).

According to a research carried out by The American Academy of Pediatrics (AAP) and the American Academy of Child and Adolescent Psychiatry (AACAP) said that those children who view shows in which violence is very realistic, frequently repeated or unpunished, are more likely to imitate what they see (Alia Bibi \& Roshan Zehra, 2012). Anderson (2003) in which he showed that violence shown in television programs and video games is clear cut indication that violent contents will increase aggressive and violent behaviour of children in both short-term and long-term context.

Children who watched a lot of cartoons include violence. So, kids acquire cruelty from their funny friends by unintentional perception. For example, 'Tom and Jerry', where a cat and a mouse chase each other. It would be better to inform people why this cartoon has a downside. Tom and Jerry is a very popular cartoon. Jerry is very clever and Tom is a little bit of a fool. In this cartoon both of them fight with different tools, which seems funny. But it is dangerous for a child because at this age children learn those activities from cartoons and want to use them in real life (Aliyeva, 2013). According to the conclusions of psychologists who emphasize the negative impacts of cartoons on children, kids who watch cartoons 3-4 hours a day are prone to violence. Moreover, marginalization of cognitive functions, different from realities, and an increase of negative behavior might develop over the course of time (Aliyeva, 2013).

A case study presented by Hassan \& Daniyal (2013) stated that children are affected by their most favourite program on television i.e. cartoons. They determined the strong impact of Cartoon Network on school going kids which can be seen on their lifestyle, aggressive and violent behaviour. They found in their study that most of the kids, $80 \%$ often spent their time in watching cartoons and more Cartoon Network is the most favourite cartoon channel of $84 \%$ children. Most of the students, $65.2 \%$ spend daily 1 to 3 hours in watching cartoons on television in their leisure time. And so they have proven the facts that the most favourite hobby of the children is watching cartoon. One of the study published in the Journal Pediatrics, indicated the results of a program designed to limit the exposure of preschool children to violence-laden videos and the increase of time with educational programming that encourages empathy. They found in their experiment that the children's aggression reduced toward others, compared with a group of children who 
were allowed to watch whatever they wanted (Louis, 2013).

An additional study that generally find significant positive correlations of whether people who view many violent TV shows and movies also tend to behave more aggressively. One group of researchers in samples of Wisconsin and Maryland high school and junior high school students, studied the links between "aggressive behavioural delinquency," such as fighting and hitting, and TV violence of viewing. They found significant positive links between TV violence exposure and aggression for both boys and girls. In the past six months, another research team reported 49 percent more violent acts by heavy viewers of TV violence than by light viewers (Huff, 2010).

In one study it was also found that what a children watches on TV at age 8 will be one of the best predictors of how aggressive they will be as an adult. The children's TV viewing outweighed other factors such as child-rearing practices and socioeconomic factors. It was also found that it is not nearly as important as what they watch before age 8. Others argue that this violence numbs children to real life violence. They see the cartoon characters beating up the bad guys so when they see a bully at school picking on another kid they are less likely to find anything wrong with that situation (Krieg, 2006).

Further study by McDonough (2009) showed evidenced that American children aged 2-11 are watching more and more television than they have in years. The older sector of that group (ages 6-11) spend a little less time, about 28 hours per week watching $\mathrm{TV}$, since they are more likely to be attending school for longer hours. While $97 \%$ of kids' viewing is through live TV, younger kids spend more time than the older group viewing via DVR, DVD and, to a lesser extent, VCR. Over the 30 years, the relationship between exposure to media and aggression has been researched extensively. Different types of studies have proven a correlation. Exposure to media violence also has been associated with changes in youth attitudes about the use of violence in interpersonal relationships. While the evidence may be compelling, translation of these findings to the "real" world has been problematic. Findings are criticized on the estates that most studies were conducted under controlled laboratory conditions and focused on short-term changes in behaviour. It is unclear whether violent media has similar effects when viewed in home or community settings and whether such exposure has long-term consequences (Spring 2005).

With all this being said there are still people out there who disagree with the perception that children's cartoons are too violent. Some just simply argue that kids will be kids and that they will kick, hit and yell karate moves whether they watch TV or not (Walsh, 2014). Others such as Gerard Jones author of "Killing Monsters: Why Children need Fantasy, Super Heroes and Make-Believe Violence," state that these cartoons actually help children. Jones states that these cartoons allow children to become something that they can't be in everyday life, to leave the real world behind for a while to satisfy their own curiosity. Children can protect themselves onto these superheroes and this lets them become powerful for a few minutes in a world that gives no power to children. Jones also goes on to say that the reason why society is so against these violent cartoons is because we think it will eliminate real life violence.Some say that these cartoons give children a cathartic outlet to let out pent up aggression and fears. On the other hand others say that the TV violence is the cause of the pent up aggression to begin with (Chandler, 2014).

\section{Bullying}

Bullying on the other hand, is a form of aggressive behaviours. It includes both psychological and physical bullying-related behaviours. The psychological act of bullying includes verbal or nonphysical forms of bullying such as calling another one mean names making fun of someone, teasing, spreading false rumours, and trying to make others dislike a student. Physical bullying behaviour such as hitting, kicking, pushing, shoving, locking a person indoors, fighting and slapping. We know that bullying is serious and can be distractive to the well-being of children. Thus, bullying in the classroom prevents students from learning and teachers from teaching.

According to a new study by two U.S. researchers, children aged two to 12 are being exposed to a alarming amount of socially aggressive and bullying behaviour, parents are often warned to the regular kind of physically violent behaviour (Freeman, 2013). According to the study of Koneng Lor (2008), overall, $36.2 \%$ (199 of 554) participants reported watching 2 or more hours of TV on the previous day, and $12 \%$ reported being committers of physical bullying in the previous month. Girls and boys equally reported having watched 2 or more hours of TV on the previous day $(36.5 \%$ vs. $36.0 \%)$. Committers of physical bullying (unadjusted odds ratio $(\mathrm{OR})=3.04$, $95 \%$ confidence interval $(\mathrm{CI})=1.79-5.17)$ and students who were physically victimized $(\mathrm{OR}=1.58$, $\mathrm{CI}=1.10-2.27)$ in the previous month were significantly more likely to watch 2 or more hours of TV on the previous day. The relationship between TV viewing hours and physical bully committer persisted when stratified by gender (male-specific OR $=2.98, \mathrm{CI}$ $=1.57-5.66$, female specific $\mathrm{OR}=2.57, \mathrm{CI}=1.28$ 9.95); however, the association between TV viewing hours and physical bully victim was significant only among males $(\mathrm{OR}=2.42, \mathrm{CI}=1.45$ 4.05). After simultaneously adjusting for school, grade, and gender, TV viewing hours was significantly associated with physical bully committer $(\mathrm{aOR}=2.84, \mathrm{C} 1=1.15-5.1$ $8)$; with male physical bully victim $(\mathrm{aOR}=1.99, \mathrm{CI}=$ 1.14-3.49); and with grade $6(\mathrm{aOR}=3.00, \mathrm{CI}=1.56$ 5.76).

For the study, published in the Journal of Communication, Nicole Martins and co-author Barbara J. Wilson (2008) conducted a content analysis of the 50 most popular children's television programs according to Nielsen Media Research for the 2005 to 2006 viewing season. They found that 92 percent of the show contained some form of social aggression after they analysed the three random episodes each of the 
show. Behaviours such as gossiping and manipulation of friendships. According to the research, children who watch television more are prone to push other kids around. Conversely, four-year-olds whose parents tend to read to them, eat meals, go on outings with them together are significantly less likely to become bullies in grade school. The study followed 1,266 four-yearolds through age's six to 11 . There is an increase of 3.9 hours of TV per day led to a 25 percent increase in the possibility of becoming a bully (Britth, 2005).

According to the study of Dr. Frederick Zimmerman that for every hour of television a child watched per day, the child is nine percent more likely to become a bully. Rendering to the study of the University of Washington professor indicated that the typical fare of television that children watch has an effect on their bullying behaviour. In fact, he notes, one of the interesting things that found was its huge effect. Regarding the difference between children who watched no TV versus children who watched the typical amount of TV -- which in their sample was about 3 and a half hours per day -- there was about a 25 percent increased risk associated with that difference (Rettig, 2005).

Notably, however, Zimmerman points out in his study that the type of the material was not a particularly significant factor in the measurable effects of media viewing on children. That is, the results appeared to have nothing to do with the type of movies or television programming a child watched (Rettig, 2005). A study in Ohio by Singer (2006) and colleagues assessed the association between TV viewing and aggressive behaviour among $3^{\text {rd }}$ to $4^{\text {th }}$ graders; 26 however, only physical forms of bullying (referring to hitting, slapping or punching) were assessed.

One more study entitled, Association of between Screen Television Bullying Behaviour: An Analysis of Oregon Elementary School Health Behaviour Survey, 2004-05 which sought to answer the research question: Is there an association between excessive television viewing ( $\geq 2$ hours per day) and bullying behaviours among a sample of Oregon elementary school? It was accomplished using three specific aims: Specific Aim \#1: Assess unadjusted and school-adjusted associations between television viewing hours $(<2 \mathrm{hrs}$ vs $\geq 2$ hours per day) and bullying behaviours. Specific Aim \#2: Assess stratified associations between television viewing hours $(<2 \mathrm{hrs}$ vs $\geq 2$ hours per day) and bullying behaviours. Specific Aim \#3: Assess adjusted associations between television viewing hours ( $<2$ hrs vs $\geq 2$ hours per day) and bullying behaviours, while for other variables in a multivariable model (Lor, 2008).

In a study appearing in the 2008 of September issue of Perspectives on Psychological Science, a journal of the Association for Psychological Science, psychologists Seymour Feshbach from the University of California, Los Angeles and June Tangney from George Mason University investigated the effect that exposure to violent TV programs has no negative behaviour in children from different ethnic backgrounds. To investigate this connection, the psychologists conducted a study that evaluated TV viewing habits, intelligence, and behaviour in 4th, 5th and 6th grade children. To assess these qualities, the children's parents and teachers completed behavioural questionnaires detailing the children's aggression, delinquency and cruelty. The children took IQ tests and completed surveys indicating the TV programs (which were later categorized as violent or non-violent by the researchers) they had watched during a seven day time period, (Association for Psychological Science, Television Viewing and Aggression: Some Alternative Perspectives, Science Daily 6 October 2008).

\section{RESEARCH DESIGN AND METHODOLOGY}

This research will use a correlation research design. This will be used to determine the relationship between television viewing habits and bullying acts of the respondents.

\section{Locale of the Study}

This study will be conducted to the intermediate grade school children from Kabacan Pilot Central School (SY 2015-2016). This school will be chosen to be the locale of the study because the researcher can generalized the population of the school age children in this school. The population of the pupils is large enough to give the researcher a sufficient number of subjects needed for the study.

\section{Respondents and Sampling Procedure}

The respondents of this study are the selected intermediate grade school children from Grades 4 to 6 in KPCS, Kabacan, Cotabato. The respondents will be selected using stratified random with proportional allocation sampling to ensure representativeness of the grade school children from the target population. Slovin's formula will be used to determine the number of respondents of the study.

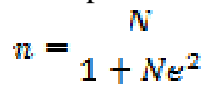

$$
\begin{aligned}
& \text { Where: } \\
& \mathrm{n} \text { = sample size desired } \\
& \mathrm{N}=\text { population size } \\
& \text { e }=\text { desired margin of sampling error }
\end{aligned}
$$

\section{Research Instrument}

The researcher and her adviser prepared a short checklist consisting of the different cartoon shows on TV and the time they spend in watching cartoons based on daily and weekends schedule. And the television program watched by the intermediate grade school children.

The second instrument to be used is the Illinois Bullying Scale (IBS), an 18-item test that contains three subscales for measuring the frequency of the fighting peer victimization. It consist of 9 items indicating the Bully subscale that includes items that address how often a youth (8-18 years old) engaged in a bullying behaviour, primary in the form of social aggression. The other 4 items consist of the victim subscale that includes items that address both physical 
and verbal types of victimization by peers and the remaining 5 items determines the physical fighting behaviour.

\section{Data Gathering Procedure}

A letter of permission will be obtained by the researcher from the office of the dean and the offices of the district superintendent and principal of the school. During the conduct of the study, the researcher will distribute the questionnaires on television viewing habits to the selected respondents through the class advisers from grade 4 to 6 . In gathering data regarding the level of bullying of the respondents, they will be carefully assisted by the researcher, with the help of facilitators to read and explain important information using the Illinois Bully Scale.

\section{Statistical Analysis}

This research will utilize frequency distribution and percentages and to determine the television viewing habits of the respondents. And Chisquare test of independence will be used to determine the possible relationship of TV viewing and the level of bullying of the respondents.

\section{RESULTS AND DISCUSSIONS}

This study attempted to examine the relationship between television viewing habits and bullying of intermediate grade school children in Kabacan, Pilot Central School. Specifically, this study aimed to (1) determine the television viewing habits of the respondents (which included the number of hours in watching TV and the TV programs watched); (2) determine the level of bullying of the respondents; and (3) determine the significant relationship between television viewing habits and the level of bullying of the respondents.

The television viewing habits (number of hours in watching TV) of the intermediate grade school children in Kabacan Pilot Central School (SY 20152016).

In order to provide data for the first objective of this study on the television viewing habits of the respondents, the data was presented using the Table 1.a for the number of hours spent on TV and Table 1.b for TV programs the respondents watched on TV. Table 1.a presents that on the daily basis majority of the respondents or $156(51.1 \%)$ of them watched TV for two (2) hours. The other 81 or $26.6 \%$ spent 3 hours, 29 or $9.5 \%$ watched for four (4) hours, while 18 or $5.9 \%$ spent only one (1) hour and the remaining 12 or $3.9 \%$ and 9 or $3 \%$ spent five (5) and six (6) hours respectively.

On weekly basis, the result is the same with the television viewing habits on the daily basis. Based on the result, most of the respondents i.e. 121 or $39.7 \%$ also spent two (2) hours watching TV per week. The other 88 or $28.9 \%$ of the intermediate grade school children spent 3 hours, 59 or 19.3 spent four (4) hours, 19 or $6.2 \%$ watched TV for five (5) hours and the rest of them (11 or $3.6 \%$ and 7 or $2.3 \%$ ) spent up to 6 hours and only 1 hour respectively per week. Additionally, the data also presents the average per week television viewing habit of the respondents, and it revealed that there were many of them (104 or $34.1 \%$ ) watched TV for three (3) hours. The other 63 or $20.7 \%$ watched TV for four (4) hours and the same frequency was obtained from the respondents who watched five (5) hours (63 or $20.7 \%$ ), and 32 or $10.5 \%$ of the students spent two (2) hours and the remaining two (2) or $0.7 \%$ of them said that they only spent 1 hour as average of TV viewing habit per week.

The discussion of this research focused only on the TV programs which were the cartoon shows wherein the students were presented of the list of cartoon shows and were asked to check the cartoons they watched on daily and weekly bases and the average of TV viewing per week. The result implies that majority of the respondents' (who were the intermediate grade school children in Kabacan Pilot Central School) television viewing habit was two (2) hours for both daily and weekly and the average per week of TV viewing habit was three (3) hours.

Based on the available literature, the same as adults, the children of today are watching TV more than ever. This is because of the availability of the TV sets everywhere. According to the study of the National Television Violence here in the Philippines (2005), $50 \%$ of TV programs contain violence. The average number of violent incident is 6.2 incident per hour. Four every hour of TV viewing there are 6.2 incidents. Violence occurs most often in action/ adventure programs $(31.6 \%)$ unlike any other genre. And cartoon shows contain some action and adventure.

Further, if students are exposed to cartoons with violent contents this way, they might be obsessed with the thought of them. For example, in the available literature one of the studies showed that teachers noticed that children had been more obsessed that ever with cartoon characters; they wrote stories, drew pictures, and built models of their favourite characters while in school. Another, in a survey conducted to 56 elementary teachers, $88 \%$ reported that they were concerned about the effects of cartoons such as the Power Rangers on their students. Of those teachers surveyed, $96 \%$ of them reported that violence had increased among children in their classes, recently. They also noticed that in the playgrounds that boys were increasingly excluding the girls in their play (Walsh, 2014).

Moreover, children who watched a lot of cartoons can also view violence, because cartoons recently had been found out to have violent contents, for instance, 'Tom and Jerry', where a cat and a mouse that chase each other. It would be better to inform people why this cartoon has a downside. Tom and Jerry is a very popular cartoon. Jerry is very clever, while Tom is a little bit of a fool. In this cartoon, both of them fight with different tools, which seem funny. But it is dangerous for a child because at this age, children learn those activities from cartoons and want to use them in real life (Aliyeva 2013). 
Table 1.a

The television viewing habits (number of hours in watching TV) of the intermediate grade school children in Kabacan Pilot Central School (SY 2015-2016)

\begin{tabular}{lcc}
\hline \multicolumn{1}{c}{ TV Viewing Habits } & Frequency $(\mathbf{N}=\mathbf{3 0 5})$ & Percentage $(\boldsymbol{\%})$ \\
\hline Number of Hours Watching TV & & \\
\hline DAILY & 18 & 5.9 \\
1 hour & 156 & 51.1 \\
2 hours & 81 & 26.6 \\
3 hours & 29 & 9.5 \\
4 hours & 12 & 3.9 \\
5 hours & 9 & 3.0 \\
6 hours & & 2.3 \\
\hline WEEKLY & 7 & 39.7 \\
1 hour & 121 & 28.9 \\
2 hours & 88 & 19.3 \\
3 hours & 59 & 6.2 \\
4 hours & 19 & 3.6 \\
5 hours & 11 & 0.7 \\
6 hours & & 10.5 \\
\hline AVERAGE PER WEEK & 2 & 34.1 \\
1 hour & 32 & 20.7 \\
2 hours & 104 & 20.7 \\
3 hours & 63 & 13.4 \\
\hline hours & 63 & \\
6 hours & 41 & \\
\hline
\end{tabular}

Table 1.b

The television viewing habits (TV programs watched) of the intermediate grade school children in Kabacan Pilot Central School (SY 2015-2016)

\begin{tabular}{lcc}
\hline \multicolumn{1}{c}{ TV Viewing Habits } & Frequency $(\mathbf{N}=\mathbf{3 0 5})$ & Percentage $(\boldsymbol{\%})$ \\
\hline NETWORKS & & \\
\hline 1. BROADCAST & 90 & 29.5 \\
1 hour & 161 & 52.8 \\
2 hours & 50 & 16.4 \\
3 hours & 2 & 0.7 \\
4 hours & 2 & 0.7 \\
5 hours & & \\
\hline 2. CABLE & 148 & 48.5 \\
1 hour & 76 & 24.9 \\
2 hours & 48 & 15.7 \\
3 hours & 33 & 10.8 \\
\hline hours & & \\
\hline
\end{tabular}

Further, it is believed that the required number of hours a student spends in school in the elementary level, according to the Department of Education in Philippines, is more or less 8 hours (beginning from 7 am to $4 \mathrm{pm}$ ). As observed, most children - given that play time defines their world, engage oftentimes into outdoor or indoor games with their friends and/or neighbours while some other choose to watch cartoon shows on TV or play electronic games. In watching cartoon programs that contain violence, children run the risk of viewing violent contents on TV that might possibly lead them to become aggressive on their ways and become bully.

And remarkably on this note, according to the conclusions of psychologists who emphasize the negative impacts of cartoons on children, kids who watch cartoons 3-4 hours a day are prone to violence. Moreover, marginalization of cognitive functions, different from realities, and an increase of negative behavior might develop over the course of time (Aliyeva, 2013). Additionally and also to provide further data for the first objective of this study, Table 1.b shows that majority of the respondents spent two (2) hours (i.e. 161 or $52.8 \%$ ) watching Broadcast TV networks. The other 90 or $29.5 \%$ of the students spent only one (1) hour and 50 or $26.4 \%$ of them spent three (3) hours, and the remaining four (4) or two (2) for each of the respondents spent 4 to 5 hours.

For the students who watched Cable TV, they spent one (1) hour on TV i.e. 148 or $48.5 \%$ of them. The 76 or $24.9 \%$ of respondents spent two (2) hours and the rest of the 48 or $15.5 \%$ and the other 33 or $10.8 \%$ watched three (3) and four (4) hours respectively. In order to elicit the responses of the students based on the television viewing habits on the cartoon programs watched, they were asked to check if they watch cartoon programs played on the Broadcast TV Networks and/or on the Cable TV Networks (see Checklist of the cartoon shows played on the different Broadcast TV Networks, such as the ABS-CBN, GMA, and TV5; and the different Cable TV Channels, namely, the Disney Channel, Cartoon Network, Hero TV, and Nickelodeon). This implies that the intermediate grade school children in Kabacan Pilot Central School were watching two (2) hours of cartoon shows on TV Broadcast and only one (1) hour for children who were viewing cartoon shows on the Cable TV. 
Additional data is presented to bring forth more substance in the discussion for the first objective of this study. The questionnaire used was developed and designed to determine the frequency and behaviours of the intermediate grade school children in their habit of watching television. The data also made important contributions by determining the frequency of watching TV among the respondents. The most remarkable findings in Table 1.c were reflected on the averages found on the last column. One, is the statement number 6, which was the statement that, "they stayed up late watching their favourite shows on TV" which is very often. Additionally is the item number 9, which stated that, "they spent most of their leisure time watching TV". And only one statement, i.e. the number 7 revealed that they seldom "memorized the schedule of TV programs on various channels that they like". And all other statements (see survey questionnaire on the Appendices) were believed to be very seldom.

Table 1.c

The television viewing habits (frequency of watching TV) of the intermediate grade school children in Kabacan Pilot Central School (SY 2015-2016)

\begin{tabular}{ccccccccccc}
\hline \multirow{2}{*}{ Statements } & \multicolumn{3}{c}{$\mathbf{1}$} & \multicolumn{3}{c}{$\mathbf{2}$} & \multicolumn{3}{c}{$\mathbf{3}$} & \multicolumn{3}{c}{$\mathbf{4}$} & \multirow{2}{*}{ Average* $^{*}$} \\
\cline { 2 - 9 } & $\mathbf{F}$ & $\mathbf{\%}$ & $\mathbf{F}$ & $\mathbf{\%}$ & $\mathbf{F}$ & $\mathbf{\%}$ & $\mathbf{F}$ & $\mathbf{\%}$ & \\
\hline 1. & 69 & 22.6 & 117 & 38.4 & 38 & 12.5 & 81 & 26.6 & 2 \\
2. & 75 & 24.6 & 99 & 32.5 & 64 & 21.0 & 67 & 22.0 & 2 \\
3. & 86 & 28.2 & 113 & 37.0 & 29 & 9.5 & 77 & 25.2 & 2 \\
4 & 92 & 30.2 & 106 & 34.8 & 46 & 15.1 & 61 & 20.0 & 2 \\
5. & 73 & 23.9 & 92 & 30.2 & 63 & 20.7 & 77 & 25.2 & 2 \\
6. & 83 & 27.2 & 84 & 27.5 & 54 & 17.7 & 84 & 27.5 & $2 ; 4$ \\
7. & 101 & 33.1 & 99 & 32.5 & 47 & 15.4 & 58 & 19 & 1 \\
8. & 87 & 28.5 & 100 & 32.8 & 52 & 17 & 66 & 21.6 & 2 \\
9. & 59 & 19.3 & 95 & 31.1 & 52 & 17 & 99 & 32.5 & 4 \\
10. & 51 & 16.7 & 93 & 30.5 & 69 & 22.6 & 92 & 30.2 & 2 \\
\hline Legend: & & & & & & & & &
\end{tabular}

1 - Seldom

2 - Very seldom

3 - Often

4 - Very Often

Table 1.d

The television viewing habits (behaviors in watching TV) of the intermediate grade school children in Kabacan Pilot Central School (SY 2015-2016)

\begin{tabular}{|c|c|c|c|c|c|c|c|c|c|}
\hline \multirow{2}{*}{ Statements } & \multicolumn{2}{|c|}{1} & \multicolumn{2}{|c|}{2} & \multicolumn{2}{|c|}{3} & \multicolumn{2}{|c|}{4} & \multirow{2}{*}{ Average* } \\
\hline & $\mathbf{F}$ & $\%$ & $\mathbf{F}$ & $\%$ & $\mathbf{F}$ & $\%$ & $\mathbf{F}$ & $\%$ & \\
\hline 1. & 74 & 24.3 & 89 & 29.2 & 54 & 17.7 & 88 & 28.9 & 2 \\
\hline 2. & 54 & 17.7 & 78 & 25.6 & 63 & 20.7 & 110 & 36.1 & 4 \\
\hline 3. & 62 & 21 & 80 & 26.2 & 62 & 20.3 & 99 & 32.5 & 4 \\
\hline 4 & 64 & 21 & 89 & 29.2 & 72 & 23.6 & 80 & 26.2 & 2 \\
\hline 5. & 87 & 28.5 & 78 & 25.6 & 69 & 22.6 & 71 & 23.3 & 1 \\
\hline 6. & 64 & 21 & 101 & 33.1 & 70 & 23 & 70 & 23 & 2 \\
\hline 7. & 77 & 25.2 & 111 & 36.4 & 49 & 16.1 & 68 & 22.3 & 2 \\
\hline 8. & 76 & 24.9 & 99 & 32.5 & 53 & 17.4 & 77 & 25.2 & 2 \\
\hline 9. & 86 & 28.2 & 96 & 31.5 & 55 & 18 & 68 & 22.3 & 2 \\
\hline 10. & 59 & 19.3 & 110 & 36.1 & 71 & 23.3 & 65 & 21.3 & 2 \\
\hline 11. & 61 & 20 & 85 & 27.9 & 89 & 29.2 & 70 & 23 & 3 \\
\hline 12. & 58 & 19 & 82 & 26.9 & 79 & 25.9 & 86 & 28.2 & 4 \\
\hline 13. & 53 & 19 & 82 & 26.9 & 79 & 25.9 & 86 & 28.2 & 2 \\
\hline 14. & 59 & 19.3 & 92 & 31.8 & 72 & 23.6 & 77 & 25.2 & 2 \\
\hline 15. & 54 & 17.7 & 94 & 30.8 & 79 & 25.9 & 78 & 25.6 & 2 \\
\hline 16. & 55 & 18 & 77 & 25.2 & 81 & 26.6 & 92 & 30.2 & 4 \\
\hline 17. & 47 & 15.4 & 72 & 23.6 & 93 & 30.5 & 93 & 30.5 & 3 \\
\hline 18. & 49 & 16.1 & 75 & 24.6 & 90 & 29.5 & 91 & 29.8 & 4 \\
\hline 19. & 50 & 16.4 & 86 & 28.2 & 74 & 24.3 & 95 & 31.1 & 4 \\
\hline 20. & 56 & 18.4 & 83 & 27.2 & 88 & 28.9 & 78 & 25.6 & 3 \\
\hline 21. & 49 & 16.1 & 67 & 22 & 94 & 31.1 & 95 & 31.1 & 4 \\
\hline 22. & 41 & 13.4 & 77 & 25.2 & 78 & 25.6 & 109 & 35.7 & 4 \\
\hline $\begin{array}{l}\text { om } \\
\text { seldom } \\
\text { Often }\end{array}$ & & & & & & & & & \\
\hline
\end{tabular}

Further, as shown on Table 1.d is data based on the behaviors of the respondents in their television viewing habits. As reflected on the last column of the table, are the averages of the responses made by the students. This discussion is simply presented by using the result of the averages as responded by the students in each statement. The findings revealed that statements number 2 and 3 were suggestive that, "students study homework in front of the TV set and they would rather watch TV than do homework instead". These statements are quite alarming because it might cause academic disturbance to the students.

Another was the statement number 12 which stated that, "I try to mimic what I see on TV to my 
classmates". This is an indication that if aggression and violence are shown on TV, they might have the tendency to copy or imitate the act, hence, potential for bully behaviors. Still other items that average to the responses as very often were the statement numbers 16 , $18,19,21$, and 22 . The contexts of the statements were the students "find difficulty to sleep at night without TV on", "they are not bothered seeing other being beaten by other children because they normally see it on TV", "they have learned to use insulting words as a result of TV viewing", "they enjoyed calling names on their classmates cause they see it on TV", and lastly, "they have tried to play pranks or physical jokes on their classmates". All of these items are potential for bullying behaviors and indications that these children might be problems in their school and at home. Further, all other statements in the behavior components of watching TV fell within the very seldom responses.

The level of bullying of the intermediate grade school children in Kabacan Pilot Central School (SY 2015-2016)

In order to determine the level of bullying among the respondents, a survey questionnaire which was the Illinois Bully Scale (IBS) was used. It contained 18 items that contained three subscales for measuring the frequency of fighting peer victimization. It consisted of 9 items indicating the Bully subscale. As shown on Table 2 is the level of bullying of the intermediate grade school children. The discussion on this result is based on the interpretation of the instrument which ranges from 0-36 for the bullying subscale. There are no clear-cut categories of the levels of bullying and the only available interpretation of the scale is the high scores reflect high levels of bullying. Hence, the discussion focused mostly on the bully subscales.

Result revealed that majority of the respondents fell within the range of $0-4$ in their level of bullying i.e. 173 or $56.72 \%$ the other 67 or $21.97 \%$ had 5-9 levels of bullying, 31 of them scored between 1014 levels of bullying, and 22 others fell within 15-19 levels. Moreover, it is important to note that the remaining eight (8) or $2.62 \%$ were within $20-24$, while or the remaining four (4) students were within 25-34, which indicated high scores in the level of bullying. And the average score or the median of the respondents was four (4) meaning, more than half of the respondents scored low in the level of bullying. The result implies that the level of bullying of the intermediate grade school children in Kabacan Pilot Central School were within low and average. Although only very few had indications of high levels of bullying, it poses increasing interest and concerns among educators and psychologists.

Table 2

The level of bullying of the intermediate grade school children in Kabacan Pilot Central School (SY 2015-2016)

\begin{tabular}{ccc}
\hline Level of Bullying & Frequency $(\mathbf{N}=\mathbf{3 0 5})$ & Percentage $(\%)$ \\
\hline $0-4$ & 173 & 56.72 \\
$5-9$ & 67 & 21.97 \\
$10-14$ & 31 & 10.16 \\
$15-19$ & 22 & 7.21 \\
$20-24$ & 8 & 2.62 \\
$25-29$ & 2 & 0.66 \\
$30-34$ & 2 & 0.66 \\
\hline
\end{tabular}

The Relationship between the television viewing habit and level of bullying of the intermediate grade school children in Kabacan Pilot Central School (SY 2015-2016).

The Broadcasting TV Networks that were identified in the checklist of the TV programs were Broadcasting TV Network 1 (ABS-CBN), Broadcast TV Network 2 (GMA), and Broadcasting TV Network
3 (TV5). The results revealed that only the Broadcasting TV Network 2 (GMA) which obtained the values of $\mathrm{t}=10.394$, $\mathrm{p}$-value $=0.000<0.05$ and the Broadcasting TV Network 3 (TV5) obtained scores such as $\mathrm{t}=1.99, \quad \mathrm{p}$-value $=0.047<0.05$ significantly influenced the level of bullying of the respondents. This indicates that the Broadcasting TV Network a child viewed had influenced his/her level of bullying.

Table 3.a

The relationship between the television viewing habit (Broadcasting TV Network) and level of bullying of the intermediate grade school children in Kabacan Pilot Central School (SY 2015-2016)

\begin{tabular}{|c|c|c|c|c|}
\hline \multirow{2}{*}{ Variable } & \multicolumn{2}{|c|}{ Unstandardized Coefficients } & \multirow{2}{*}{$\mathbf{T}$} & \multirow{2}{*}{ p-value } \\
\hline & $\mathbf{B}$ & Std. Error & & \\
\hline Broadcast N 1 & .809 & .823 & $.983^{\mathrm{ns}}$ & .327 \\
\hline Broadcast N 2 & 5.124 & .493 & $10.394 * *$ & .000 \\
\hline Broadcast N 3 & 2.016 & 1.013 & $1.990 *$ & .047 \\
\hline
\end{tabular}

Dependent variable is Bullying Level

Ns - not significant at $5 \%$ level of significance

**highly significant at $1 \%$ level of significance

*significant at $5 \%$ level of significance

The result implies that children who were watching Broadcasting TV Network 3 or TV5 had higher level of bullying than those children who were watching Broadcasting TV Network 2 or GMA. The cartoon programs showed on TV5 on weekdays included, HI-5 Hulk and the Agent of S.M.A.S.H., Jake 
and the Netherland Pirates Looney Tune Marvel's Agents of S.H.I.E.L.D. Marvel's X-Men, Randy Cunningham: $9^{\text {th }}$ Grade Ninja, Scooby Doo! Mystery Incorporated, and Teacher's Pet. Additionally, on weekends on TV5 were Ben 10, Henry Hugglemonster, HI-5, Jhonny Bravo, Little Einstein, Magical Doremi, Sofia The First, Scooby-Doo! Mystery Incorporated and Sword Art Online. The significant relationship between the television viewing habits in terms of cartoons watched may be because of the varied number and varied choice of cartoons showed. On the other hand, cartoons shown on weekdays on GMA were Dragon Ball, Fairy Tail, Hunter X Hunter, Knockout, and Toriko. On weekends, programs like Angry Birds, Cross Fight B-Daman, Dragon Ball, Grimm's Fairy
Tale, Kemmen Rider 000 and Pac-Man and the Ghost Adventures were shown.

However, we cannot make any conclusions on children who were watching Broadcasting TV Network 1 or ABS-CBN since the result showed that it was not significantly correlated to the level of bullying. The cartoon program shown on weekdays on ABS-CBN was only the Power Ranger Mega Force. On weekends were Kung Fu Panda Max Steel, Sponge Bob Square Pants and the flying House. Considering the number and variety of cartoon programs shown on GMA and TV5, it may be the possible reason why the result on the relationship between television viewing habit and bullying were significant. On the other hand, another result on the relationship will also be discussed.

Table 3.b

The Relationship between the television viewing habit (Cable TV Network) and level of bullying of the intermediate grade school children in Kabacan Pilot Central School (SY 2015-2016)

\begin{tabular}{|c|c|c|c|c|}
\hline \multirow{2}{*}{ Variable } & \multicolumn{2}{|c|}{ Unstandardized Coefficients } & \multirow{2}{*}{$\mathbf{t}$} & \multirow{2}{*}{ p-value } \\
\hline & $\mathbf{B}$ & Std. Error & & \\
\hline Cable N 1 & 4.277 & .504 & $8.491 * *$ & .000 \\
\hline Cable N 2 & 2.872 & .872 & $3.291^{* *}$ & .001 \\
\hline Cable N 3 & 1.914 & 1.026 & $1.866^{\mathrm{ns}}$ & .063 \\
\hline Cable N 4 & 3.942 & 1.195 & $3.29 * *$ & .001 \\
\hline
\end{tabular}

Dependent variable is Bullying Level

Ns - not significant at $5 \%$ level of significance

**highly significant at $1 \%$ level of significance

In this discussion data is discussed separately from the Broadcast TV Network. The relationship of the two variables is discussed based on the availability of the Cable TV Networks at home among the intermediate grade school children. The Cable TV Networks that were identified in the checklist were the Cable TV Network 1 (Disney Channel), Cable TV Network 2 (Cartoon Network), Cable TV Network 3 (Hero TV). The results revealed that the Cable TV Network 1 or the Disney Channel $(\mathrm{t}=8.491$, $\mathrm{p}$ value $=0.000<0.05)$, Cable TV Network 2 or the Cartoon Network $(\mathrm{t}=3.291$, $\mathrm{p}$-value $=0.001<0.05)$ and Cable TV Network 4 or Nickelodeon $(\mathrm{t}=3.29$, pvalue $=0.001<0.05$ ) significantly influenced the level of bullying of the respondents. This indicates that the Cable TV Network a child viewed had influenced his/her level of bullying.

Further, the results revealed that children who were watching Cable TV Network 4 or Nickelodeon had higher levels of bullying than those children who were watching Cable TV Network 2 or Cartoon Network and Cable TV Network 1 or Disney. While, children who were watching Cable TV Network 2 or Cartoon Network had higher levels of bullying than those children who were watching Cable TV Network 1 or Disney Channel. However, we cannot make any conclusion on children who were watching Cable Network 3 or the Hero TV since it had no correlation to the level of bullying.

\section{Summary of Findings}

The study on "Television Viewing Habits and Bullying of intermediate Grade School Children in Kabacan Pilot Central School", specifically aimed to (1) determine the television viewing habits of the respondents (which included the number of hours in watching TV and TV programs watched); (2) determine the level of bullying of the respondents; (3) and determine the relationship between television viewing habits and the level of bullying of the intermediate grade school children.

This study used a checklist to determine the number of hours the respondents watched TV on the Broadcast TV Network and Cable TV Network which show cartoon programs. Another, the study used the Illinois Bullying Scale (IBS) to measure the bullying behaviours of the respondents. The study was conducted among the selected intermediate grade school children from Grades 4 to 6 in KPCS, Kabacan, Cotabato who were enrolled in the SY 2015-2016. Slovin's formula was used to determine the number of respondents needed in the study. The current research utilized frequency distribution and percentages. The Ch-square of independence was used to determine the possible relationship of TV viewing and level of bullying of the respondents. The gathered data which was analyzed yielded the following results:

1. The findings to show results for the first objective of this study were divided into four (4):

a. First, (findings on the number of hours spent in watching TV) on the daily basis majority of the respondents or $156(51.1 \%)$ of them watched TV for two (2) hours; on weekends, most of the respondents i.e. 121 or $39.7 \%$ also spent two (2) hours watching TV per week; and the data also presents the average per week television viewing habit of the respondents, and it revealed that there were many of them (104 or $34.1 \%$ ) watched TV for three (3) hours. 
b. Second, (TV programs watched): majority of the intermediate grade school children in Kabacan Pilot Central School were watching two (2) hours of cartoon shows on Broadcast TV Networks and only one (1) hour for children who were viewing cartoon shows on the Cable TV Networks.

c. Third, (frequency of watching TV) another data also made remarkable findings and were reflected on the averages and the respondents believed that very often "they stayed up late watching their favourite shows on TV", but they seldom "memorized the schedules of TV programs on various channels that they like".

d. Fourth, (behaviors in watching TV): the respondents believed that very often, "they spent most of their leisure time watching TV", "students study homework in front of the TV set and they would rather watch TV than do homework instead", "I try to mimic what I see on TV to my classmates", "find difficulty to sleep at night without TV on", "they are not bothered seeing other being beaten by other children because they normally see it on TV", "they have learned to use insulting words as a result of TV viewing", "they enjoyed calling names on their classmates cause they see it on TV", and lastly, "they have tried to play pranks or physical jokes on their classmates".

2. The result revealed that majority of the respondents fell within the range of $0-4$ in their level of bullying i.e. 173 or $56.72 \%$ which was interpreted as having low level of bullying.

3. The results revealed that only the Broadcasting TV Network 2 (GMA) which obtained the values of $\mathrm{t}=10.394, \quad \mathrm{p}$-value $=0.000<0.05$ and the Broadcasting TV Network 3 (TV5) obtained scores such as $\mathrm{t}=1.99$, $\mathrm{p}$-value $=0.047<0.05$ significantly influenced the level of bullying of the respondents; and the results further revealed that the Cable TV Network 1 or the Disney Channel $(\mathrm{t}=8.491$, $\mathrm{p}$-value $=0.000<0.05)$, Cable TV Network 2 or the Cartoon Network $(\mathrm{t}=3.291$, p-value $=0.001<0.05)$ and Cable TV Network 4 or Nickelodeon $\quad(t=3.29, \quad p$-value $=0.001<0.05)$ significantly influenced the level of bullying of the respondents.

\section{CONCLUSIONS}

Based on the result, it can be concluded that the level of bullying of the intermediate grade school children in Kabacan Pilot Central School were within low and average. Although only very few had indications of high levels of bullying, it poses increasing interest and concerns among educators and psychologists. The result further concludes that children who were watching Broadcasting TV Network 3 or TV5 had higher level of bullying than those children who were watching Broadcasting TV Network 2 or GMA, however, we cannot make any conclusions on children who were watching Broadcasting TV
Network 1 or ABS-CBN since the result showed that it was not significantly correlated to the level of bullying. Additionally, the results conclude that children who were watching Cable TV Network 4 or Nickelodeon had higher levels of bullying than those children who were watching Cable TV Network 2 or Cartoon Network and Cable TV Network 1 or Disney. While, children who were watching Cable TV Network 2 or Cartoon Network had higher levels of bullying than those children who were watching Cable TV Network 1 or Disney Channel. However, we cannot make any conclusion on children who were watching Cable Network 3 or the Hero TV since it had no correlation to the level of bullying.

\section{RECOMMENDATIONS}

In view of the findings and conclusion, the study recommends the following: (1) it is suggested to replicate this study to focus specifically on the cartoon shows viewed on TV by the intermediate grade school children to also specifically pinpoint the possible influence of cartoon on the level of bullying of the children; and (2) since, this research discovered children with high level of bullying, the result may be sent to the office of the principal in order to inform the class adviser of the children and provide the data to the parents for possible interventions because it might spread bullying in school as a whole.

\section{REFERENCES}

[1] Anderson, C., (2003). The influence of media violence on youth. Psychological Science in the Public Interest.

[2] Benham, Barbara.2001. Warning: Cartoons That Are Too Violent. Family Matters: News \& Views.

[3] Bibi, A., \& Zehra, R., ( 2012). The Effects of Violence in Children Cartoons: Psychology.

[4] Clark, L., (2009). For The Daily Mail. Referencehttp://www.dailymail.co.uk/news/article1159766/Cartoon-violence-makes-childrenaggressive.html

[5] Chandler, D., (1992). Television Violence and Children? Behaviour. http://www.aber.ac.uk/media/Modules/TF33120/tvviolence_and_kids.html

[6] Freeman, J., (2012). CTV News Published EDT. Reference: http:// ctvnews.ca/health/healthheadlines/bullying-aggressive-behaviour-rampant-inchildren-s-shows-study-1.976431

[7] Ginmann, M., (2003). Cartoons as information. Journal of Information Science. (29)1: 69-77Saturnine. The Adverse Effectsof Cartoons on the Minds of our Children. Paper presented at aToon-agedy Conference in Estonia.

[8] Hassan, A., \& Daniyal, M., (2013). Cartoon Network and its Impact on Behavior of School Going Children: A Case Study of Bahawalpur, Pakistan.

[9] Krieg,F., \& Grace, K., (2006) Beware The Power Rangers. Newsmagazine. 23(11).

[10] Koneng, L., (2008). Association between screen television and bullying behavior an analysis of Oregon elementary school Health behavior Survey.

[11] Ozmer, E., \& Toyran, M., \& Yurdakok, K., (2002). Behavioral correlates of television viewing in primary school children evaluated by the Child Behavior Checklist. Arch PediatrAdolesc Med.; 156: 910-914. 
[12] Osorio, B., (2012) COMMONNESS (The Philippine Star) | Updated and Kantar World Panel's 2012 Quarter 1 Urban Rural Home Panel gives us a Inurban and rural Philippines.

[13] Pediatr, J., (2001). American academy of pediatrics: Children, Adolescents, and television; 107:423-426

[14] Stabile, C., \& Harrison, M., (2003). Prime time animation; Television animation and American culture. Routledge. 71.
[15] Walsh, K., (2014). Bullying on Teen Television: Patterns across Portrayals and Fan Forum Posts. Masters Theses 1896 - Paper 960. http://scholar works. umass. edu/theses/960.

[16] Zimmerman, FJ.,\& Glew, GM., \& Christakis DA., (2005). Early cognitive stimulation, emotional support, and television watching as predictors of subsequent bullying among grade-school children. Arch Pediatr Adolesc

159(4):384-388. 